NBER WORKING PAPER SERIES

\title{
THE ROLE OF SKILL VERSUS LUCK IN POKER: EVIDENCE FROM THE WORLD SERIES OF POKER
}

\author{
Steven D. Levitt \\ Thomas J. Miles \\ Working Paper 17023 \\ http://www.nber.org/papers/w17023
NATIONAL BUREAU OF ECONOMIC RESEARCH
1050 Massachusetts Avenue \\ Cambridge, MA 02138
}

May 2011

We would like to thank Carter Mundell for truly outstanding research assistance. The views expressed herein are those of the authors and do not necessarily reflect the views of the National Bureau of Economic Research.

NBER working papers are circulated for discussion and comment purposes. They have not been peerreviewed or been subject to the review by the NBER Board of Directors that accompanies official NBER publications.

(C) 2011 by Steven D. Levitt and Thomas J. Miles. All rights reserved. Short sections of text, not to exceed two paragraphs, may be quoted without explicit permission provided that full credit, including (C) notice, is given to the source. 
The Role of Skill Versus Luck in Poker: Evidence from the World Series of Poker

Steven D. Levitt and Thomas J. Miles

NBER Working Paper No. 17023

May 2011

JEL No. K23,K42

\begin{abstract}
$\underline{\text { ABSTRACT }}$
In determining the legality of online poker - a multibillion dollar industry - courts have relied heavily on the issue of whether or not poker is a game of skill. Using newly available data, we analyze that question by examining the performance in the 2010 World Series of Poker of a group of poker players identified as being highly skilled prior to the start of the events. Those players identified a priori as being highly skilled achieved an average return on investment of over 30 percent, compared to a -15 percent for all other players. This large gap in returns is strong evidence in support of the idea that poker is a game of skill.
\end{abstract}

Steven D. Levitt

Department of Economics

University of Chicago

1126 East 59th Street

Chicago, IL 60637

and NBER

slevitt@midway.uchicago.edu

Thomas J. Miles

University of Chicago

tmiles@law.uchicago.edu 
Until recently, millions of American consumers played poker online, spending an estimated \$6 billion a year on the activity, despite the obstacles to playing posed by the 2006 passage of the Unlawful Internet Gambling Enforcement Act (UIGEA). While the UIGEA does not make it illegal for individuals to play online poker for real money, it is illegal for banks and other financial institutions in the U.S. to process transactions with online gambling sites. Federal authorities recently indicted executives of the three leading online poker sites that allow Americans to play. ${ }^{2}$ In response, these poker sites stopped accepting American players, but vowed to demonstrate the legality of online poker.

While many arguments can be made for and against UIGEA, the single most important factor in determining the legality of poker is whether poker is a game of skill or a game of luck. The UIGEA defines unlawful internet gambling as transmitting through the internet a wager that is illegal under state or federal law. Under state law, courts have evaluated the legality of a game by asking whether it is dominated by skill or luck. The federal statute's own definition of gambling or wagers (risking something of value upon a game of chance with an agreement that certain values will be given for particular outcomes of the game) is itself borrowed from state definitions of gambling. This definition makes the legality of poker under federal law also depend on a skill-versus-luck inquiry. Whether the UIGEA governs online poker therefore hinges on whether poker is a game of skill or chance.

The UIGEA remains controversial. Immediately upon its passage, calls began for the repeal of the UIGEA. In fact, a bill to legalize and regulate online poker, H.R. 2267, was passed by the House Financial Services Committee in July of 2010. With the arrival of a new Congress in 2011, the legislation was reintroduced in the committee, H.R. 1174, and it is currently awaiting action.

\footnotetext{
2 Matt Richtel, “U.S. Cracks down on Online Gambling,” New York Times, April 15, 2011, at B1.
} 
Despite the central role that the skill versus luck dichotomy has played in legal rulings with respect to poker, there is little academic research on the subject. State courts that have ruled on whether poker is a game of skill-versus-luck generally have done so in the absence of any statistical evidence, and often they have treated all types of poker games alike. ${ }^{3}$ A highly popular poker game online is Texas Hold ' $\mathrm{Em}$, and the few cases that consider its permissibility have generated sharp dissents on whether skill dominates luck in the game. ${ }^{4}$

A small literature has emerged that attempts to test the importance of skill in poker. Cabot and Hannum (2005) conduct computer simulations of repeated rounds of Texas Hold 'Em and seven-card stud with players following "skilled” or "unskilled” strategies. In their simulations, skilled players earned as much as 10 times that of the unskilled. Dedonno and Detterman (2008) conducted experiments in which participants played hundreds of hands of Texas Hold 'Em poker, and some participants received instruction on poker strategy while others did not. They found that participants receiving instruction outperformed the contol group. These studies reinforce a point which should be clear from introspection: there are ways to play quite poorly in poker which ensure that the individual loses money (e.g., folding every hand). Less obvious based purely on introspection is whether, among the set of individuals actually engaged in playing poker for high stakes, there is a large role for skill. Especially relevant to this question is the recent work of Croson et al. (2008) which analyzes finish positions of individual players across 81 high-stakes poker tournaments, conditional on a player "making the money" in that tournament, i.e. finishing roughly in the top ten percent of all entrants. The idea underlying the

\footnotetext{
${ }^{3}$ Early state court decisions contained strong pronouncements about poker and have proven highly influential on subsequent courts. City of Shreveport v. Bowen, 40 So. 859 (La. 1906) ("[I]t is a matter of common knowledge concerning which there can be no doubt or dispute that draw poker is a gambling game, pure and simple”); Ginsberg v. Centennial Turf Club, 251 P.2d 926 (Colo. 1952) ("No one would contend that a game of poker, in which money is bet on the relative value of cards dealt by participants, constitutes a lottery, but it is most certainly gambling”).

${ }^{4}$ People v. Mitchell, 444 N.E.2d 1153 (Ill.App. 1983); Garrett v. State, 963 So.2d 700 (Ala.Crim.App. 2007).
} 
paper is that positive serial correlation in outcomes across tournaments is an indicator of skill. In those cases where a player makes the money, both having finished in the top 18 of a previous tournament and the number of top-18 finishes in previous tournaments are found to be significantly and negatively correlated with a player's rank among the top-18 finishers in the current tournament. Also, a player's average previous rank in the top 18 is significantly and positively correlated with their rank in the current tournament.

The greatest shortcoming of the Croson et al. (2008) analysis - unavoidable because of the data available -- is that all the analysis conditions on a player making the money in a particular tournament because information on the full set of players who enter a tournament is not available. Also absent are any data regarding the number of chips that a player has amassed at intermediate points along the way in a tournament. These data limitations introduce three potential weaknesses. First, because these tournaments generally have many entrants, any given player only rarely is one of the top eighteen finishers, leading the useable information set to be quite sparse. More than two thirds of the players they observe appear in their data exactly once, and thus provide no useful identifying variation. ${ }^{5}$ Among the players who do appear on multiple occasions, roughly half appear exactly twice.

A second potential problem in the Croson et al. (2008) analysis is that the inference hinges on the assumption that, absent skill, the finish positions conditional on making the money would be randomly distributed across players. This assumption is likely to be violated if players follow different tournament strategies. The psychic benefits that players derive from just “making the money” are likely to differ substantially. For instance, amateur players who enter only a few tournaments are likely to value the bragging rights of lasting long enough to make the

\footnotetext{
${ }^{5}$ Because their measure of skill is the correlation in outcomes across tournaments, at least two observations per player are required.
} 
money more than top professionals, who recognize that the highly convex distribution of payouts mean that winning an occasional tournament is far more important to long term profits than a steady diet of finishes in the lower half of the top eighteen. Players who are focused on winning are likely to pursue a riskier strategy that, all else equal, leads them to be eliminated earlier in the tournament in return for having a greater number of chips down the stretch on those occasions when they survive to the end. Because the Croson et al. (2008) analysis is done conditional on finishing in the top eighteen, holding skill constant, players following riskier strategies will appear to perform better even if their strategy has the same unconditional expected value, leading to a spurious upward bias in their estimate of skill.

Finally, since the Croson et al. (2008) data do not include information on who enters tournaments, they are unable to estimate the return on investment (ROI) across players. ${ }^{6}$ ROIs provide a more direct and intuitive metric for quantifying skill than correlations.

In this paper, we take advantage of newly available information from the 2010 World Series of Poker (WSOP) to improve on the methodology of Croson et al. (2008). ${ }^{7} \quad$ For the first time, complete lists of all players who entered each of the 57 tournaments that comprise the WSOP were made available in 2010. As a consequence, we are able to compute ROIs for individual players, allowing us to measure poker skill more directly than in previous research. We identify sets of players who, based on information available prior to the start of the 2010 WSOP, could reasonably be classified as being especially skilled (e.g. players who were top money winners in the 2009 WSOP, or those who appear in one of the published lists of the most highly ranked poker players). We then compare the ROIs achieved by these selected players

\footnotetext{
${ }^{6}$ Players pay an entrance fee to participate in these tournaments. The venue that runs the event keeps a small portion of the entrance fees; with the remainder returned as prize money. Typically, no outside money is added to the prize pool, meaning that on average players earn a negative ROI due to the venue keeping some of the entry fee. ${ }^{7}$ Neither these specific data nor anything comparable were available at the time that Croson et al. (2008) was published.
} 
relative to other players. The greater the difference in ROI's across the two groups, the greater the implied skill differential. To the extent that our classification of poker players into "skilled" versus “unskilled” is inevitably quite noisy, our estimates represent a lower bound on the true amount of skill that is present.

Our empirical findings suggest a substantial role for skill in poker over the time horizon examined. The 720 players identified $a$ priori as being high-skilled generate an average ROI of 30.5 percent in the 2010 WSOP, reaping an average profit of over $\$ 1,200$ per player per event. ${ }^{8}$ In contrast, all other players obtain an average ROI of -15.6 percent, implying a per event loss of over \$400. The observed differences in ROIs are highly statistically significant and far larger in magnitude than those observed in financial markets where fees charged by the money managers viewed as being most talented can run as high as three percent of assets under management and thirty percent of annual returns.

The remainder of the paper is structured as follows. Section II provides background on the World Series of Poker and the data set used in the analysis. Section III presents the empirical findings. Section IV concludes.

\section{Section II: Background and Data}

Each summer, a series of poker tournaments known as the World Series of Poker are held in Las Vegas. In 2010, the WSOP included nearly 57 separate tournaments, more than 32,000 participants, and more than \$185 million in prize money. The WSOP culminates with a final tournament known as the "Main Event;” the winner of this event earns nearly $\$ 9$ million.

The poker tournaments that make up the WSOP share a basic structure. Players wishing to participate in a tournament pay an entry fee ranging between $\$ 1,000$ and $\$ 50,000$. Almost all

\footnotetext{
${ }^{8}$ Events last an average of three days, but the majority of players are eliminated within the first day, so the typical entrant spends slightly less than one day playing poker per event.
} 
WSOP events are open to any player who pays the entry fee. In return for the entry fee, each player is given a pre-determined number of chips and randomly assigned to a poker table. A player remains in the tournament until all of his chips are lost, at which time the player is eliminated. Play proceeds until one player collects all of the chips, with all other competitors having been eliminated. That player is the winner. The other players' ranks are based on the length of time that a player survives before losing all chips. The last player to lose all his/her chips finishes second; the first player to run out of chips is the last-place finisher. Most of the WSOP events take two or three days (with pre-specified breaks) to complete, although the Main Event, which allots more chips to each player and attracts larger numbers of players, takes two weeks.

Entry fees paid by competitors fund the prize pool, with some proportion of the fees (on average 7.5 percent) going to the venue in which the WSOP is held. The payoff structure in WSOP events is highly convex, as demonstrated in Figure 1 which presents the distribution of earnings for a typical tournament. The vertical axis shows a player's net payoff (winnings minus entry fee). The horizontal axis represents the player's order of finish, with the winning player on the far right of the graph. Figure 1A presents the distribution for all players in the typical tournament, and Figure 1B presents the distribution for just players between the top 75 and 500 finishers. Roughly 90 percent of the players in any given tournament receive no prize money, and thus suffer a net loss equal to their entry fee. Those who are paid are said to be "in the money.” There is a discontinuity in payoffs between those who just make the money and those who are eliminated "on the bubble." Those who just make the money receive roughly 2 times their initial entry fee in prize money, while those knocked out earlier receive nothing. The value of prizes then increases relatively slowly until the very top spots are reached, after which prizes 
accelerate sharply. For instance, in the event pictured, which is typical of other events, the player who finished in $200^{\text {th }}$ place received roughly $\$ 2,700$, the $100^{\text {th }}$ place finisher received $\$ 3,000$, and the winner took home $\$ 571,000$. The combination of a discontinuity in payoffs upon "making the money” and convexity in payoffs thereafter has an important influence on strategy. As the number of players remaining approaches the number of players who will receive prize money, those competitors with relatively few chips may find it optimal to play very cautiously, sacrificing expected value in order to survive long enough to make the money. ${ }^{9}$ This provides the players with deep stacks of chips an opportunity to play especially aggressively, leading to a very wide spread of chips at the time when the field shrinks to the point where positive payoffs begin.

The WSOP attracts a large number of participants. Figure 2 presents the distribution of the number of events played by individuals. In total, over 32,000 people competed in at least one WSOP event in 2010. Approximately two-thirds of these players entered exactly one event. The 10 percent of players who play the most events comprise 45 percent of all entries into the WSOP. Playing in a large number of events entails a substantial financial investment: one individual spent more than $\$ 260,000$ on entry fees in the 2010 WSOP. $^{10}$

We make use of six data sources to serve as a proxy for which poker players are most skilled. Three of these rankings are drawn from published lists of top players in 2009, one compiled by BLUFF magazine, a second by the website PokerPages.com, and the last by Card Player Magazine. Of the 250 highest ranked players on each of these lists, more than 200

\footnotetext{
${ }^{9}$ This tendency is exacerbated by the fact that the number of times a player makes the money is tracked as a statistic and is readily available online. Making the money may also have other psychic benefits - poker players loath being the player knocked out "on the bubble," which involves playing 20 or more hours of poker over two days with nothing to show for it. The data presented below suggest this tendency is much more pronounced among the less skilled poker players.

${ }^{10}$ That player earned $\$ 437,000$ in prize money. The biggest loser in the 2010 WSOP paid in $\$ 252,000$ in entry fees, but earned only $\$ 24,000$ in prize money.
} 
competed in at least one 2010 WSOP event and thus were included in our sample. Our fourth proxy drew names from the Player of the Year rankings in the eighth season of the World Poker Tour, a series of televised international poker tournaments. Only 110 players from this ranking system had "Player of the Year Points" greater than 0, and of these 86 competed in at least one 2010 WSOP event. Our final two proxies for poker skill are based on performance in previous years' WSOPs. As one measure of past performance, we included as "high skill” anyone who had won a WSOP event prior to 2010. Such players are known as "bracelet winners" because the victor in each event receives a bracelet as well as a cash prize. There were a total of 556 past winners, 311 of whom participated in at least one WSOP in 2010 and thus are included in our data. The last measure of skill is being among the top 250 money winners in the 2009 WSOP. ${ }^{11}$ Table 1 presents the correlation matrix across our six proxies for poker skill. There is positive correlation across all of the proxies, as would be expected, with the greatest overlap $(\rho>.50)$ observed for the three published measures of the current top 250 players.

\section{Section III: Results}

Table 2 presents the basic findings for the data used in the analysis. The first column shows data for all competitors. Columns 2 and 3 divide the sample into two mutually exclusive groups: those who do not qualify as "high skill" by any of our proxies, and those who do qualify. The remaining six columns report summary statistics for the six individual high skill proxies. These last six columns are not mutually exclusive because there is overlap across the proxies. A total of 32,496 players appear in the data, 720 of whom are classified as "high skill" according to at least one of our proxies. Although only about two percent of the entrants are in the high skill

\footnotetext{
11 The 250th money winner in 2009 won $\$ 118,000$ in prize money. Average prize money across this group in 2009 was $\$ 426,000$.
} 
category, because these players enter six times as many tournaments on average as other players, the high skill players represent 12.1 percent of all the tournament entries.

The results with respect to poker skill are presented in the bottom seven rows of Table 2 . Rows 4 and 5 present measures of the frequency with which these players make the money and make the final table respectively, compared to what would be predicted if there was no skill in poker. The results are normalized so that a value of 1.00 represents the average in the data. Consequently, by definition, in column 1 for the sample as a whole the value shown is $1.00 .^{12}$ Players classified as high skill are 12 percent more likely to make the money than the average player, and 19 percent more likely to make the final table.

The next four rows show dollars spent on buy-ins and dollars received in prize money. High skill players invest nearly ten times as much on average in buy-ins (both because they enter more events and because on average the events they enter have higher buy-ins), but they are paid out fourteen times as much as other players. Totaled across all players in a category, the low skill players lose almost \$26 million dollars (for a return on investment of -15.6 percent). In contrast, the high skill players net a profit of nearly \$11 million (for a return on investment of 30.5 percent). This difference in return on investments is evidence of skill in poker, since a set of pre-determined proxies for skill prove to be correlated with future returns. Five of the six proxies for skill are associated with a positive ROI, with the Bluff Top 250 list yielding the highest return on investment - more than 36 percent. $^{13}$

The results in Table 2 are heavily influenced by one of the 57 tournaments that make up the WSOP; that tournament is known as the "Main Event.” The Main Event has a high buy-in

\footnotetext{
${ }^{12}$ We report this normalization, rather than the raw likelihoods of making the money or the final table because highskill and low-skill players play in tournaments with different average field sizes. Because the number of players at the final table is fixed, a lower share of entrants make the final table in larger tournaments.
} 
and a large number of competitors, so that fully 36 percent of the money invested by players across all the tournaments goes towards that one event. Results excluding the Main Event are shown in Table 3. High skill players continue to outperform other players when the Main Event is excluded, but the gaps are smaller: 9.8 percent ROIs for high skill players versus -13.8 percent ROIs for other players.

The returns on investment reported above can be translated into dollar returns per tournament. The high skill players earn an average return of over $\$ 1,200$ per tournament in profit (\$350 excluding the Main Event) versus a loss of over $\$ 400$ per tournament (\$235 without the main event) for other players. The amount of time it takes to play an event is a function of how long the player survives before being eliminated. On average, an entrant would expect to survive about one day's worth of play, implying substantial wages for the skilled players.

\section{Section IV: Conclusion}

This paper attempts to shed light on the extent to which pre-existing metrics of poker skill are useful in predicting tournament outcomes. Our results suggest that players who are $a$ priori identified as "high skill" do indeed substantially outperform other competitors. This predictability in returns is evidence for a substantial role of skill in poker.

It is not immediately obvious how one measures the importance of skill versus luck in poker relative to other activities. One approach that problem is to estimate the probability that a randomly drawn high skill poker player will outperform a randomly drawn low-skilled poker player over the course of a tournament. An important limitation of our data in this regard is that we do not observe the complete order of finish, but rather, only the order of finish for those who make the money. Because of this limitation, we can make pairwise comparisons between two 
players in a tournament only when at least one makes the money. Subject to that constraint, an exhaustive pairwise comparison of high skilled and low skilled players entered in each tournament in the WSOP finds that the high skilled player wins 54.9 percent of the match ups. For purposes of comparison, we calculated the regular season win rates for professional sports teams that made the playoffs in the previous season - making the playoffs last year is akin to being a highly skilled player entering the WSOP. Since the year 2007, teams that made the playoffs the previous season win 55.7 percent of their games in Major League Baseball against teams that failed to make the playoffs in the previous year. Thus, in some crude sense, the predictability of outcomes for pairs of players in a poker tournament is similar to that between teams in Major League Baseball. To the extent that baseball would unquestionably be judged a game of skill, the same conclusion might reasonably be applied to poker in light of the data.

Asset management is another domain where skill is generally believed to be important, as evidenced by consumers paying billions of dollars annually in fees to money managers. Academic analysis, however, has generally found little evidence for skill in this domain as demonstrated by low rates of persistence in mutual fund returns (Carhart 1997, Bollen and Busse 2004) and evidence of inferior or superior performance only in the extreme tails of the mutual fund distribution (Fama and French 2010). 


\section{$\underline{\text { References }}$}

Bollen, Nicolas P.B. and Jeffrey A. Buse, 2004, “Short-term Persistence in Mutual Fund Performance,” Review of Financial Studies 18(2):569-597.

Cabot, Anthony and Robert Hannum, 2005, “Poker: Public Policy, Law, Mathematics, and the Future of an American Tradition,” Thomas M. Cooley Law Review 22(3):443-513.

Carhart, Mark M., 1997, “On Persistence in Mutual Fund Performance,” The Journal of Finance 52(1):57-82

Croson, Rachel, Peter Fishman, and Devin G. Pope, 2008), “Poker Superstars: Skill or Luck?” Chance 21(4):25-8.

Dedonno, Michael and Douglas K. Detterman, 2008, “Poker Is a Skill,” Gaming Law Review 12(1):31-36.

Fama, Eugene F., and Kenneth R. French, 2010. “Luck versus Skill in the Cross-section of Mutual Fund Returns,” The Journal of Finance 65(5):1915-1947.

Cases

City of Shreveport v. Bowen, 40 So. 859 (La. 1906).

Garrett v. State, 963 So.2d 700 (Ala.Crim.App. 2007).

Ginsberg v. Centennial Turf Club, 251 P.2d 926 (Colo. 1952).

People v. Mitchell, 444 N.E.2d 1153 (Ill.App. 1983). 


\section{Figure 1A: Typical Cash Structure}

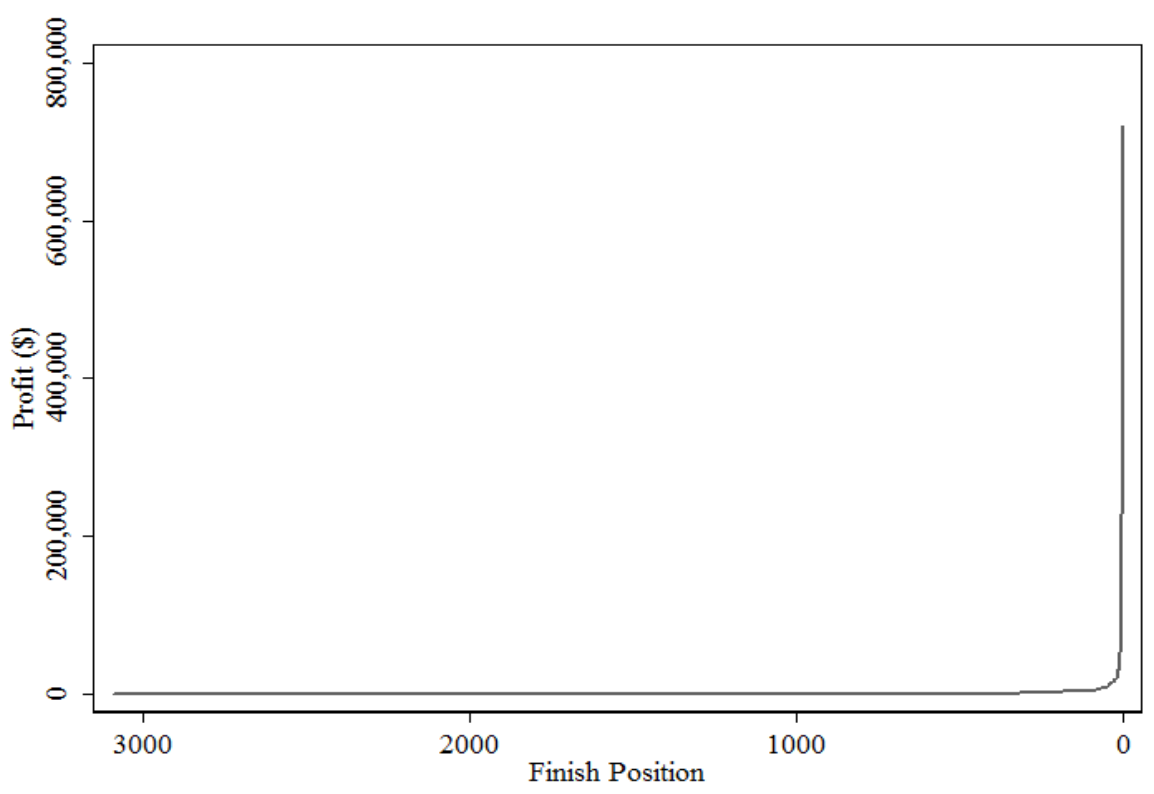

Figure 1B: Typical Cash Structure (Discontinuity)

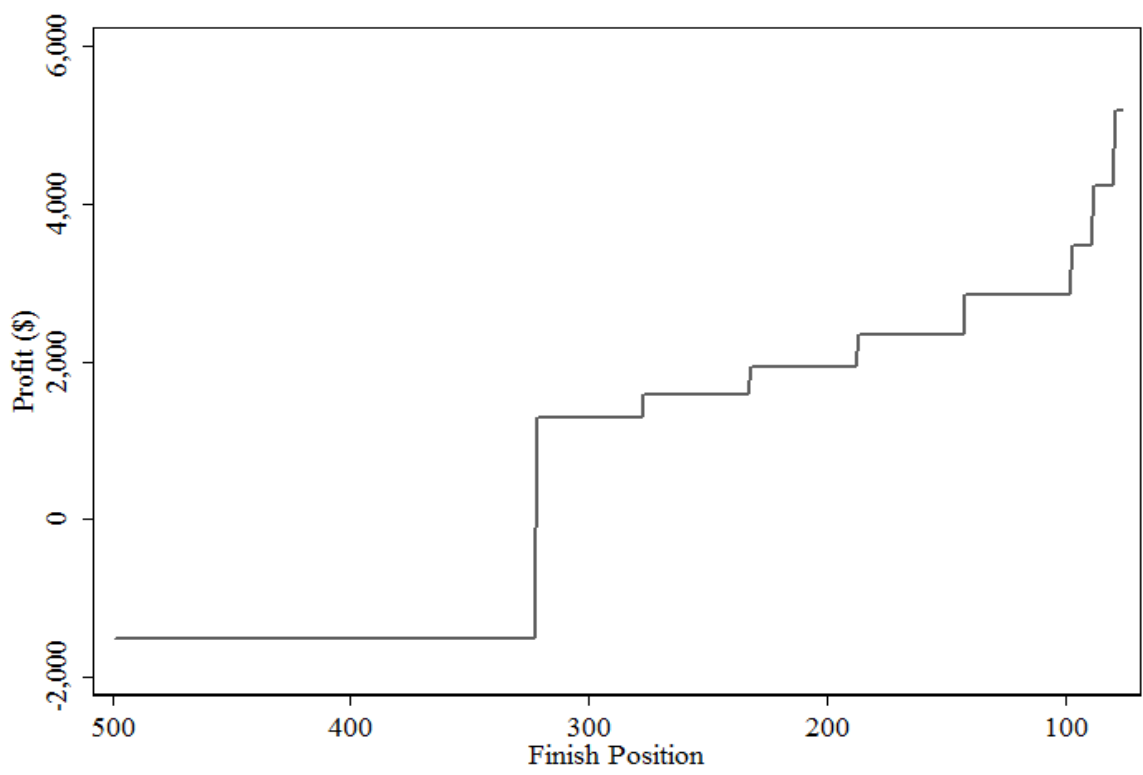

Notes: Figure 1 presents the distribution of earnings for a typical poker tournament. The vertical axis shows a player's net payoff (winnings minus entry fee), and the horizontal axis shows the player's order of finish, with the winning player on the far right of the graph. Figure 1A presents the distribution for all players in the typical tournament, and Figure 1B presents the distribution for just players between the top 75 and 500 finishers. 
Figure 2: Number of Events Entered Per Player

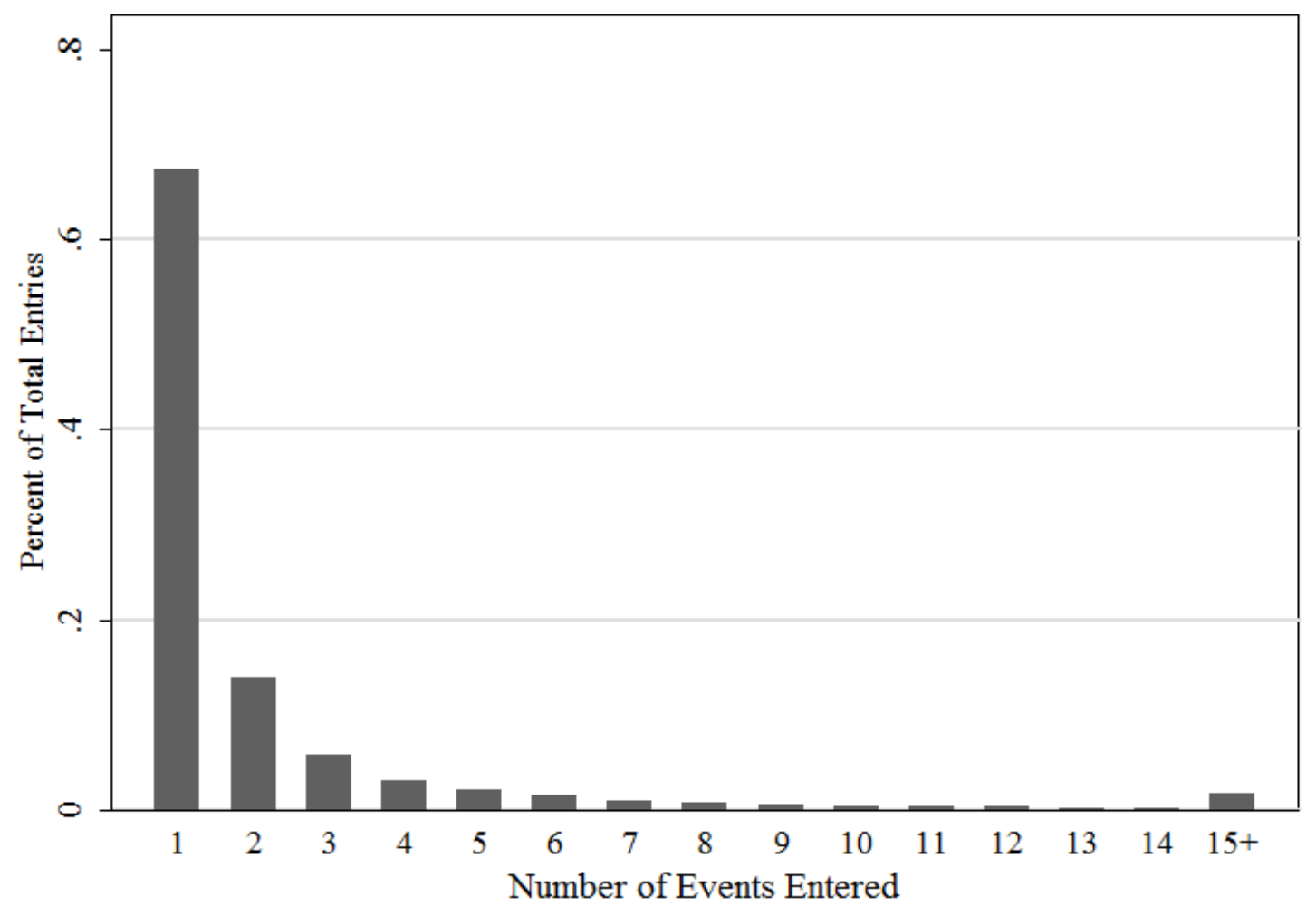

Notes: Figure 2 presents the distribution of events played by the 32,496 individual participants in the tournaments of the 2010 World Series of Poker. 
Table 1: Correlation Matrix for "High Skill" Proxies

\begin{tabular}{|c|c|c|c|c|c|c|}
\hline & $\begin{array}{c}\text { BLUFF Top } \\
250\end{array}$ & Pro Rank & $\begin{array}{c}\text { Card Player } \\
\text { Top } 250\end{array}$ & $\begin{array}{c}\text { World Poker } \\
\text { Tour }\end{array}$ & $\begin{array}{c}\text { WSOP } 2009 \\
\text { Top Money } \\
\text { Winners }\end{array}$ & Past Winners \\
\hline BLUFF Top 250 & 1 & & & & & \\
\hline Pro Rank & 0.643 & 1 & & & & \\
\hline Card Player Top 250 & 0.646 & 0.566 & 1 & & & \\
\hline World Poker Tour & 0.221 & 0.178 & 0.228 & 1 & & \\
\hline WSOP 2009 Top Money Winners & 0.380 & 0.327 & 0.405 & 0.081 & 1 & \\
\hline Past Winners & 0.267 & 0.223 & 0.221 & 0.118 & 0.255 & 1 \\
\hline
\end{tabular}

Notes: Table 1 presents the correlation matrix across six proxies for poker skill for players who participated in the 2010 World Series of Poker. The first three proxies were drawn from published lists of top players in 2009: a ranking was compiled by BLUFF magazine, another by the website PokerPages.com, and a third by Card Player Magazine. The fourth proxy is a Player of the Year ranking in the eighth season of the World Poker Tour, a series of televised international poker tournaments. The fifth proxy is the top 250 money winners in the 2009 World Series of Poker, and the last is so-called "bracelet winners" who are players who have won the World Series of Poker before 2010 . 
Table 2: Summary Statistics and Results

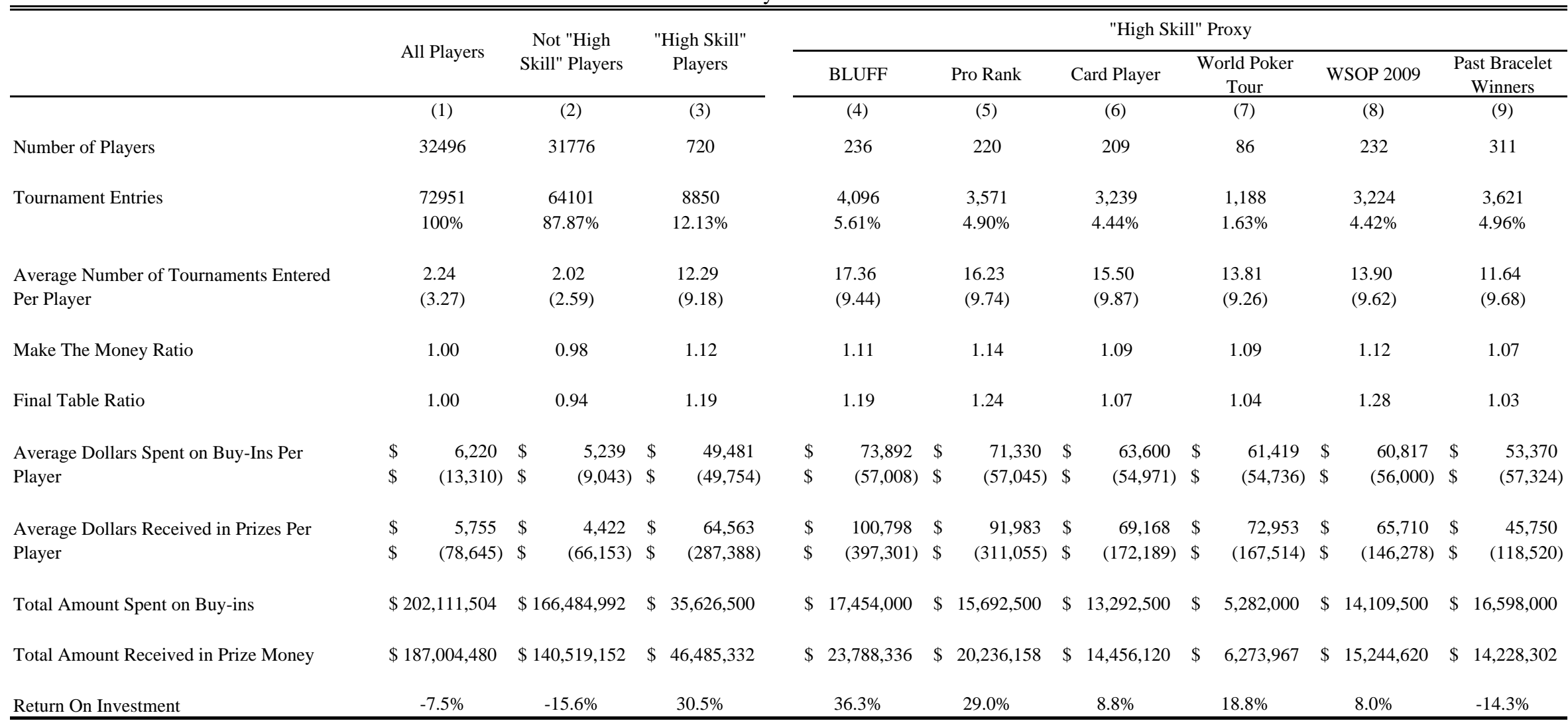

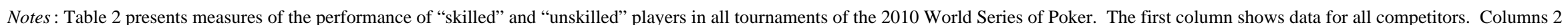

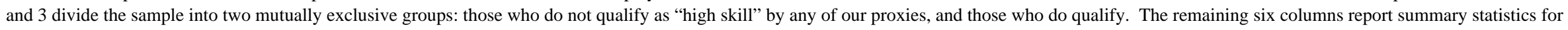

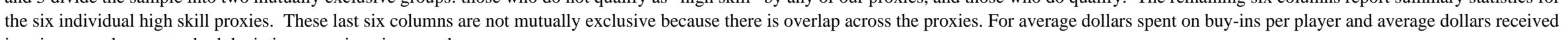
in prizes per player, standard deviations are given in parentheses. 
Table 3: Summary Statistics and Results Excluding the Main Event

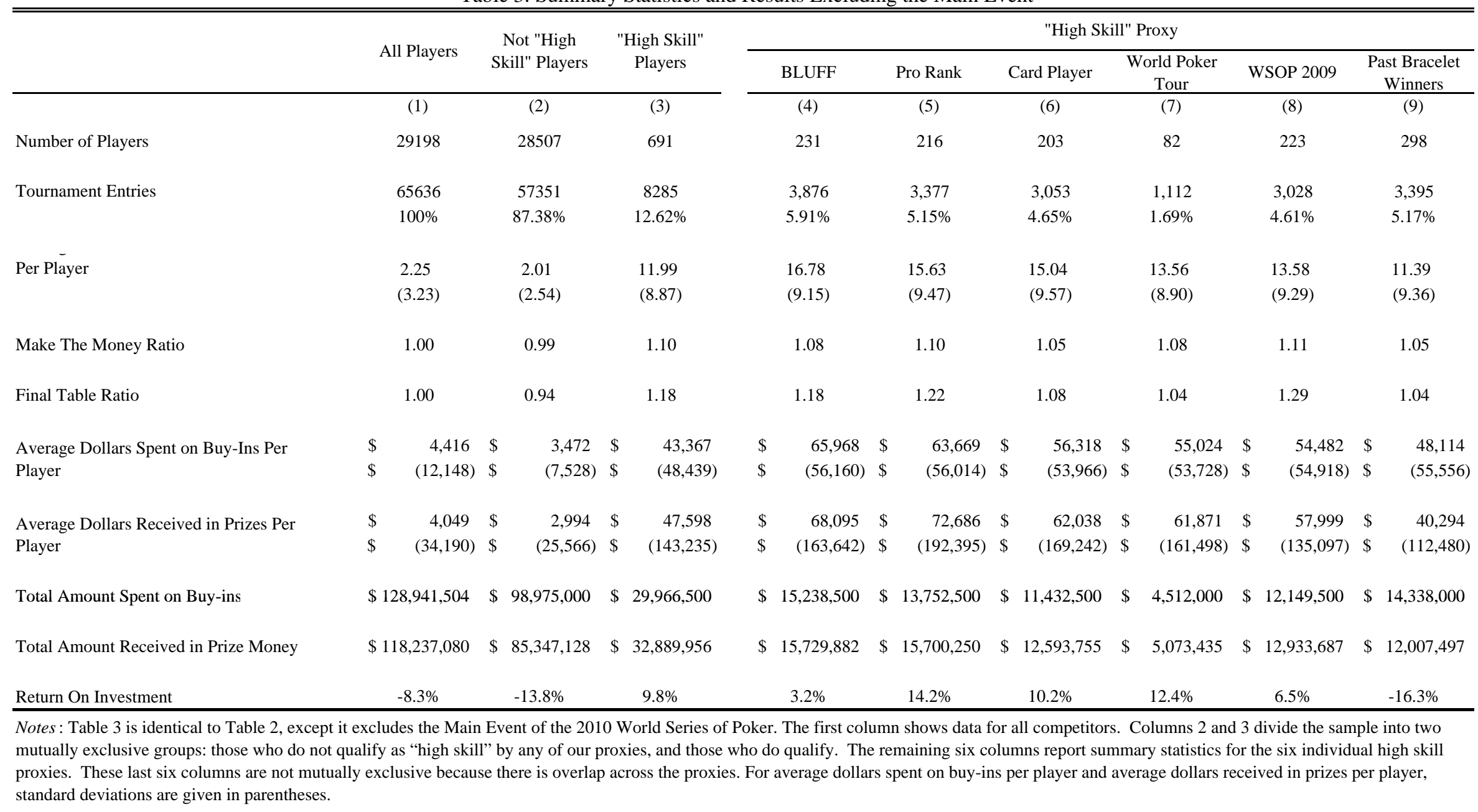

